\title{
Does Body Mass Index in Pregnant Women Affect Laboratory Parameters in the Newborn?
}

\author{
Marjana Jerković Raguž, MS ${ }^{1} \quad$ Jerko Brzica, $\mathrm{MD}^{1}$ \\ ${ }^{1}$ Department of Neonatology and Intensive Care Unit, Clinic for \\ Children's Diseases, University Clinical Hospital Mostar, Mostar, \\ Bosnia and Herzegovina
}

Am J Perinatol Rep 2016;6:e155-e159.

\begin{abstract}
Address for correspondence Marjana Jerkovic Raguz, MS, Department of Neonatology and Intensive Care Unit, Clinic for Children's Diseases, University Clinical Hospital Mostar, Mostar, Bosnia and Herzegovina (e-mail: marjanajerkovic@yahoo.co.uk).
\end{abstract}

\begin{abstract}
Keywords

- pregnancy

- obesity

- ferritin

Objective The objective of this study was to determine the effect of body mass index (BMI) during pregnancy in laboratory parameters in the serum of the three groups of pregnant women and in their newborns.

Methods This prospective study is comparison between the three groups of pregnant women and their newborns categorized according to their BMI. The study included 128 pregnant women and their newborns. In this study, the concentration of blood count, iron, ferritin, and bilirubin were analyzed in the subjects.

Results The pregnant women in the three groups significantly differ in the values of blood count $(p<0.001)$. Statistically significant difference in iron and ferritin was not found between individual three studied groups of pregnant women $(p=0.947)$. The newborn of the first group of pregnant women had significantly lower values of ferritin $(p<0.001)$, leucocytes $(p<0.001)$, and bilirubin $(p<0.001)$. Significant positive correlation between BMI of pregnant women and leucocytes, ferritin, and bilirubin of the newborn was found $(p<0.001)$.

Conclusion In this study, the tested pregnant women do not have biochemical signs of anemia, neither do their newborns. It was noted that there was no negative correlation between individual tested biochemical parameters for anemia in pregnant women and their newborns.
\end{abstract}

Current studies have shown that being overweight is a pathological condition which has its consequences not only on the health of pregnant women but also of their newborns. ${ }^{1}$ Despite results that hepcidin is a significant indicator of iron in serum of the newborn, ${ }^{2,3}$ ferritin is the most sensitive indicator of status of iron and hemoglobin in pregnant women and the newborn. ${ }^{4}$ As iron is an important factor in the development of brain and structure of blood cells, further studies on the impact of overweight in pregnancy on the change of values of iron status parameters of the newborn are necessary. ${ }^{5,6}$ Elevated body mass index (BMI) in pregnancy is an independent risk factor for a lower concentration of iron in their newborns, as shown in results of a study performed in the United States in 2014. ${ }^{7}$ The researches show that the level of iron and ferritin is significantly affected by the habit of consuming cigarettes during pregnancy. ${ }^{8}$ Concentration of hepcidin at the end of pregnancy is lower so that iron would be as accessible to the newborn as possible. ${ }^{9}$ Significant correlation exists between the level of hepcidin in pregnant women with higher body mass and their newborns but without any influence on the level of ferritin and iron. ${ }^{2}$ The impact of fat tissue on the concentration of ferritin and iron in the newborn has not been explored precisely due to possible changed transfer through umbilical cord of overweight pregnant woman, which is shown in a study by Dao et al. ${ }^{3}$ Mother's overweight is an independent factor for complications at childbirth as well as for the development of hyperbilirubinemia. ${ }^{10}$ Due to higher values of bilirubin, it is received

September 12, 2015

accepted after revision

February 26, 2016

published online

xxxx
Dol http://dx.doi.org/

10.1055/s-0036-1582135. ISSN 2157-6998.
Copyright (c) 2016 by Thieme Medical Publishers, Inc., 333 Seventh Avenue, New York, NY 10001, USA. Tel: +1(212) 584-4662.
License terms

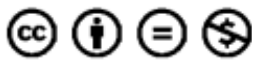


necessary to start therapy in a timely manner and prevent consequences on the brain of the newborn. Due to the problems present in everyday practice, results of the study gave a more precise insight into dynamics of values of iron, ferritin, and bilirubin in overweight pregnant women and their newborns. Therefore, monitoring the newborn is inevitable to make a correct decision on the possible monitoring or treatment.

\section{Objectives}

The objectives of this study were as follows:

1. To determine the values of iron, ferritin, and complete blood count in serum of the studied three groups of pregnant women and their newborns.

2. To determine the values of bilirubin on the second and third days of life (by noninvasive method-bilitest (Drägerwerk AG \& Co., KGaA, Lübeck, Germany)) in the studied groups of the newborn.

\section{Hypothesis}

Obesity in pregnancy suppresses the transfer of iron and in such way decreases parameters of iron status (blood count, iron, and ferritin) in the early neonatal age. As addition, overweight affects creating a higher concentration of indirect bilirubin in the newborn, which must be treated.

\section{Methods and Examinees of the Study}

A prospective study of pregnant women and their newborns was conducted at the Clinic of Gynecology and Obstetrics of the University Clinical Hospital Mostar. This is a cohort study of three groups of pregnant women categorized according to their BMI before birth. The study included healthy pregnant women who were admitted to the hospital because of the term of births, 24 to 48 hours before giving birth and retained 48 hours after birth.

The study included 128 pregnant women. The first group consists of women who had a normal body weight before birth (BMI $18.5-24.9 \mathrm{~kg} / \mathrm{m}^{2}$ ), the second group consists of pregnant women who were overweight (BMI > 25.0-29.9 $\mathrm{kg} / \mathrm{m}^{2}$ ), and the third group consists of obese women (BMI $>30 \mathrm{~kg} / \mathrm{m}^{2}$ ) before birth. The study included all healthy pregnant women who had an elevated BMI in the several days or hours before giving birth. Study groups were pregnant women older than 18 years and younger than 45 years, regardless of parity, women who were physically and mentally healthy. The pregnant women must not have a diagnosis of metabolic syndrome nor gestation diabetes. The pregnant women of the three study groups were included in the study if during pregnancy they did not have any pathological laboratory finding or any significant inflammation. The study included pregnant women who have not developed complications during pregnancy and delivery (vaginal or cesarean).

About 128 newborns were included in the study. All newborns of the three groups' pregnant women carried full 37 up to 42 gestation weeks, regardless of their mass, vitality at birth, and the manner of birth were included in the study. All pregnant women who had metabolic syndrome, gestation diabetes, antibiotics, anemia, rheumatic disease or chronic intestinal disease, or developed preeclampsia before giving birth were excluded from the study. Also, all women who had bleeding before birth or receiving blood preparations because of the impact on laboratory tests (blood count, iron) were excluded from the study.

The parameters which were monitored in pregnant women were as follows: number of previous births, course of pregnancy, taking medications, smoking, body weight at birth, body height, BMI, and laboratory tests (iron, ferritin, and blood count).

The parameters monitored in the newborn were gestation age, body weight, vitality, blood count, iron, ferritin, and bilirubin.

The newborns of the three study groups' pregnant women were taken blood from umbilical cord from which laboratory test of blood count, iron, and ferritin were done. Iron was determined in the laboratory with the help of photometric test by coloring and was measured on analyzer Olympus AU 680 (Beckman Coulter, Tokyo, Japan). Ferritin was determined with the help of immune-chemical method in the device Vitros eci (Orthoclinical Diagnostics Inc., NY). About 2 $\mathrm{mL}$ of vein blood were taken from the pregnant women and the newborns in glass test tubes without anticoagulant. Sample for blood count $(2 \mathrm{~mL})$ is taken in a test tube with anticoagulant (ethylenediaminetetraacetic acid). For bilirubin, bilitest device was used, which detects value of bilirubin in blood through the skin.

During the study, data from sociobiographic and from obstetrics-gynecology form were used, which were taken from each pregnant woman at admittance to hospital.

\section{Statistical Methods}

Data sets were checked for normality using the Shapiro-Wilk test. According to the results, descriptive statistics (median, interquartile range, and percentage) were calculated. Kruskal-Wallis test and Mann-Whitney $U$ test were used to determine the possible differences between the pregnant women and their newborns. The significance for all statistical tests was set at $p \leq 0.05$.

\section{Results}

The study included 128 pregnant women and their newborns. The first group included 65 pregnant women who had a normal body weight before birth (BMI $18.5-24.9 \mathrm{~kg} / \mathrm{m}^{2}$ ), the second group included 41 pregnant women who were overweight (BMI $>25.0-29.9 \mathrm{~kg} / \mathrm{m}^{2}$ ), and the third group included 22 obese pregnant women (BMI $>30 \mathrm{~kg} / \mathrm{m}^{2}$ ) before birth. Average age of pregnant women included in the study was 29 years. First pregnancy was the case in 50\% of the studied groups. By analyzing the outcome of pregnancy, 71\% of pregnant women had vaginal childbirth, while cesarean section was present in only $23 \%$ of pregnant women of the first group. The three tested groups of pregnant women consume cigarettes; therefore, there was no statistically 
Table 1 Comparison of values of iron, ferritin, and blood count in the serum of pregnant women according to their BMI

\begin{tabular}{|c|c|c|c|c|c|c|c|}
\hline \multirow[t]{2}{*}{$\begin{array}{l}\text { BMI } \\
\left(\mathrm{kg} / \mathrm{m}^{2}\right)\end{array}$} & \multicolumn{2}{|c|}{$\begin{array}{l}\text { Group 1: } \\
18.5-24.9\end{array}$} & \multicolumn{2}{|c|}{$\begin{array}{l}\text { Group 2: } \\
25.0-29.9\end{array}$} & \multicolumn{2}{|c|}{ Group 3: $>30.0$} & \multirow[t]{2}{*}{$p$-Value } \\
\hline & C & IQ & C & IQ & C & IQ & \\
\hline Iron $(\mu \mathrm{mol} / \mathrm{L})$ & 13.40 & 9.00 & 11.90 & 8.50 & 12.00 & 6.70 & 0.218 \\
\hline Ferritin $(\mathrm{ng} / \mathrm{mL})$ & 16.00 & 10.00 & 15.00 & 11.00 & 14.50 & 8.20 & 0.947 \\
\hline Erythrocytes $\left(\times 10^{12} / \mathrm{L}\right)$ & $4.00^{\mathrm{b}}$ & 0.70 & $3.90^{\mathrm{b}}$ & 0.70 & 3.15 & 0.40 & $<0.001$ \\
\hline Leukocytes $\left(\times 10^{9} / \mathrm{L}\right)$ & $7.00^{\mathrm{b}, \mathrm{c}}$ & 3.00 & $8.90^{\mathrm{b}}$ & 1.20 & 12.00 & 1.90 & $<0.001$ \\
\hline Hemoglobin $(\mathrm{g} / \mathrm{L})$ & $116.00^{\mathrm{b}}$ & 23.00 & $120.00^{\mathrm{b}}$ & 15.00 & 100.00 & 11.00 & $<0.001$ \\
\hline
\end{tabular}

Abbreviations: BMI, body mass index; C, median; IQ, interquartile range.

${ }^{a}$ Kruskal-Wallis test.

${ }^{\mathrm{b}} \mathrm{A}$ significant difference compared with group 3 .

${ }^{\mathrm{C}} \mathrm{A}$ significant difference compared with group 2 .

significant difference; $70 \%$ of women from the first group consumed cigarettes during pregnancy. By analyzing the habits of cigarettes consumption and chemical parameters by individual studied groups of pregnant women, higher value of ferritin in the three tested groups was found in women who had the habit of smoking, but the detected difference between those who smoked and nonsmokers was not statistically different, neither was in their newborns. As for body mass of the newborn of the studied groups of pregnant women, there was no statistically significant difference. The children were approximately 3,000 $\mathrm{g}$ at birth in the three tested groups of studied newborn.

\section{Comparison of Values of Iron, Ferritin, and Blood Count in the Serum of the Three Studied Groups of Pregnant \\ Women}

The pregnant women in all three groups significantly differ in the values of blood count. The pregnant women of the first group had significantly lower values of leucocytes and higher values of erythrocytes than the second and third groups of the pregnant women $(p<0.001)$. Statistically significant difference in other parameters-iron $(p=0.218)$ and ferritin was not found between individual three studied groups of pregnant women $(p=0.947)$ (-Table 1$)$.

\section{Comparison of Values of Iron, Ferritin, and Blood Count in the Serum of the Newborn of the Three Studied Groups of Pregnant Women}

The newborn of the first group of pregnant women had significantly lower values of ferritin $(p<0.001)$, leucocytes $(p<0.001)$, and bilirubin $(p<0.001)$ than the newborn of the second and third groups of pregnant women. Statistically significant difference in other parameters-iron, erythrocytes, and hemoglobin was not found between the newborns of three test groups of pregnant women $(p=0.982$, $p=0.465$, and $p=0.394$ ) (-Table 2).

\section{Correlation of Body Mass Index of Pregnant Women and Individual Laboratory Tests in the Newborn}

Significant positive correlation between BMI of pregnant women and leucocytes, ferritin, and bilirubin of the newborn was found. According to signs of the obtained correlation coefficients, it is visible that negative correlation exists only in the case of hemoglobin, that is, the higher the BMI, the lower the

Table 2 Comparison of values of iron, ferritin, and blood count in the serum of the newborn according to mother's BMI

\begin{tabular}{|c|c|c|c|c|c|c|c|}
\hline \multirow[t]{2}{*}{$\begin{array}{l}\text { BMI } \\
\left(\mathrm{kg} / \mathrm{m}^{2}\right)\end{array}$} & \multicolumn{2}{|l|}{$\begin{array}{l}\text { Group 1: } \\
18.5-24.9\end{array}$} & \multicolumn{2}{|c|}{$\begin{array}{l}\text { Group 2: } \\
25.0-29.9\end{array}$} & \multicolumn{2}{|c|}{ Group 3: > 30.0} & \multirow[t]{2}{*}{$p$-Value ${ }^{a}$} \\
\hline & $\mathrm{C}$ & IQ & $C$ & IQ & $\mathrm{C}$ & IQ & \\
\hline Iron ( $\mu \mathrm{mol} / \mathrm{L})$ & 27.00 & 10.00 & 26.50 & 7.30 & 26.00 & 15.00 & 0.982 \\
\hline Ferritin (ng/mL) & $100.00^{\mathrm{b}, \mathrm{c}}$ & 86.00 & 180.00 & 63.00 & 212.50 & 99.00 & $<0.001$ \\
\hline Erythrocytes $\left(\times 10^{12} / \mathrm{L}\right)$ & 4.70 & 1.20 & 4.80 & 0.70 & 4.80 & 0.70 & 0.465 \\
\hline Leukocytes $\left(\times 10^{9} / \mathrm{L}\right)$ & $16.30^{\mathrm{b}, \mathrm{c}}$ & 2.50 & 20.10 & 1.60 & 19.95 & 4.80 & $<0.001$ \\
\hline Hemoglobin (g/L) & 138.00 & 22.00 & 134.00 & 17.00 & 133.00 & 16.00 & 0.394 \\
\hline Bilirubin $(\mu \mathrm{mol} / \mathrm{L})$ & $120.00^{\mathrm{b}, \mathrm{c}}$ & 100.00 & $200.00^{c}$ & 82.00 & 240.00 & 75.00 & $<0.001$ \\
\hline
\end{tabular}

Abbreviations: BMI, body mass index; C, median; IQ, interquartile range.

${ }^{a}$ Kruskal-Wallis test.

${ }^{\mathrm{b}} \mathrm{A}$ significant difference compared with group 2 .

${ }^{\mathrm{C}} \mathrm{A}$ significant difference compared with group 3 . 
Table 3 Connection of BMI of pregnant women and individual laboratory tests in the newborn

\begin{tabular}{|l|l|l|l|l|l|l|}
\hline & Erythrocytes & Leukocytes & Hemoglobin & Iron & Ferritin & Bilirubin \\
\hline$R$ & 0.076 & 0.510 & -0.108 & 0.012 & 0.495 & 0.511 \\
\hline$P$ & 0.391 & $<0.001$ & 0.225 & 0.893 & $<0.001$ & $<0.001$ \\
\hline
\end{tabular}

Abbreviation: BMI, body mass index.

hemoglobin. Positive correlation was detected in other parameters, that is, the higher the mother's BMI, the higher the value of the observed parameters in the newborn ( - Table 3$)$.

\section{Comparison of Values of Iron, Ferritin, and Blood Count in the Serum of the Three Studied Groups of Pregnant Women According to Type of Delivery and Blood Loss}

Statistically significant difference in parameters: iron $(p=0.818)$, ferritin $(p=0.572)$, erythrocytes $(p=0.964)$, leukocytes $(p=0.116)$, and hemoglobin $(p=0.536)$ in the serum was not found between individual three studied groups of pregnant women according to the type of delivery and blood loss ( - Table 4 ).

\section{Discussion}

In western countries, research shows double increase in frequency of overweight and obesity in pregnant women. ${ }^{11}$ As we live in day and age when food is easily accessible, future mothers have much higher chances of becoming overweight pregnant woman and parturient woman. ${ }^{12}$ Overweight in pregnancy affects the perinatal outcome and increases the frequency of perinatal complications, ${ }^{13}$ while this study proved that the newborns in three groups were of average weight and ordinary vitality at birth. A study in Australia suggests higher frequency of cesarean sections, ${ }^{14}$ whereas our results show occurrence of $71 \%$ of vaginal childbirths in all the groups of pregnant women. While analyzing the impact of the habit of smoking cigarettes, it was noted that three studied groups of pregnant women had a higher concentration of ferritin, which is similar to other results. ${ }^{8}$

Current studies have shown that elevated BMI in pregnant women in the course of pregnancy significantly affects biochemical parameters of iron and ferritin in the sense of predisposition to development of anemia in pregnancy and lower concentration of ferritin in their newborns. ${ }^{9}$ Results of this study show that the pregnant women with elevated BMI do not have laboratory criteria for anemia and that they have equal concentration of ferritin and iron in the serum as pregnant women with normal BMI in pregnancy. A possible explanation lies in more frequent and bigger meals which contain foodstuff with a higher share of iron, consumed more frequently during pregnancy by pregnant women with a higher BMI. ${ }^{13}$

Results of the studies performed in previous years suggest negative consequences of overweight in pregnancy in the sense of lower transfer of iron over umbilical cord because of mild chronic inflammation in overweight pregnant women. ${ }^{2,3,9}$ Nevertheless, in our research, we obtained a statistically significant higher value of leucocytes as a parameter of inflammatory condition in pregnant women of the third group and higher value of ferritin in their newborns. That is, similar to a conclusion of a study conducted in 2015 that in spite of elevated BMI during pregnancy, their newborns have higher values of ferritin because of increased absorption through the placenta. ${ }^{15}$ That means that overweight in pregnancy as an indirect factor does not have a significant impact on ferritin and iron in the newborn, as shown by results of a study in New Zealand. ${ }^{16}$ The newborns of pregnant women with anemia and elevated BMI in pregnancy have lower values of iron and hemoglobin in comparison to the newborns of pregnant women without risk factors. ${ }^{17}$ In spite of conclusions about vulnerability of the newborn of overweight pregnant women, bioavailability of iron for the fetus is sufficient due to the adaptation of mother's organism in pregnancy. ${ }^{6,18}$ Results also show a higher value of bilirubin 48 hours upon childbirth in the second and third groups of the newborn who needed medical treatment, while a study in India proved that newborns are equally exposed to neonatal jaundice. ${ }^{19}$

Conclusion of this study is that in spite of an increase in BMI during pregnancy, the tested pregnant women do not have biochemical signs of anemia, neither do their newborns.

Table 4 Comparison of values of iron, ferritin, and blood count in the serum of pregnant women according to the type of delivery

\begin{tabular}{|l|l|l|l|l|l|}
\hline \multirow{2}{*}{ Childbirth } & \multicolumn{2}{|l|}{ Vaginal } & \multicolumn{2}{l|}{ Cesarean section } & \multirow{2}{*}{-Value } \\
\cline { 2 - 5 } & C & IQ & C & IQ & \\
\hline Iron $(\mu \mathrm{mol} / \mathrm{L})$ & 12.00 & 7.80 & 13.00 & 10.80 & 0.818 \\
\hline Ferritin $(\mathrm{ng} / \mathrm{mL})$ & 16.00 & 10.25 & 12.85 & 10.00 & 0.572 \\
\hline Erythrocytes $\left(\times 10^{12} / \mathrm{L}\right)$ & 3.90 & 0.80 & 3.90 & 1.20 & 0.964 \\
\hline Leukocytes $\left(\times 10^{9} / \mathrm{L}\right)$ & 8.00 & 2.80 & 9.00 & 3.65 & 0.116 \\
\hline Hemoglobin $(\mathrm{g} / \mathrm{L})$ & 110.50 & 23.00 & 113.00 & 23.00 & 0.536 \\
\hline
\end{tabular}

Abbreviations: C, median; IQ, interquartile range.

${ }^{\mathrm{a}}$ Mann-Whitney $U$ test. 
It was noted that there was no negative correlation between individual tested biochemical parameters in pregnant women and their newborns. Mother's obesity does not have a negative influence on concentration of iron and ferritin in the newborn, that is, it does not contribute to development of anemia in the tested sample. Mother's organism adapts to the needs of the newborn; therefore, bioavailability of iron and ferritin for the child is sufficient despite the effect of fat tissue on individual inflammatory mediators and regulators of iron transfer through the cord.

Results of the study will contribute to a better relation of obstetricians and neonatologists to the pregnant women with elevated BMI in the course of pregnancy, due to increasing number of available information about the negative impact of overweight on the outcome of pregnancy and the possible development of anemia in their newborns upon birth.

\section{References}

1 Khashan AS, Kenny LC. The effects of maternal body mass index on pregnancy outcome. Eur J Epidemiol 2009;24(11):697-705

2 Ervasti M, Sankilampi U, Luukkonen S, Heinonen S, Punnonen K. Maternal pro-hepcidin at term correlates with cord blood prohepcidin at birth. Eur J Obstet Gynecol Reprod Biol 2009;147(2): $161-165$

3 Dao MC, Sen S, Iyer C, Klebenov D, Meydani SN. Obesity during pregnancy and fetal iron status: is Hepcidin the link? J Perinatol 2013;33(3):177-181

4 Ances IG, Granados J, Baltazar M. Serum ferritin as an early determinant of decreased iron stores in pregnant women. South Med J 1979;72(5):591-592, 604

5 Crane JM, White J, Murphy P, Burrage L, Hutchens D. The effect of gestational weight gain by body mass index on maternal and neonatal outcomes. J Obstet Gynaecol Can 2009;31(1):28-35

6 Koenig MD, Tussing-Humphreys L, Day J, Cadwell B, Nemeth E. Hepcidin and iron homeostasis during pregnancy. Nutrients 2014; 6(8):3062-3083
7 Phillips AK, Roy SC, Lundberg R, et al.Neonatal iron status is impaired by maternal obesity and excessive weight gain during pregnancy. J Perinatol 2014;34(7):513-518

8 Pateva IB, Kerling EH, Reddy M, Chen D, Carlson SE, Tancabelic J. Effect of maternal cigarette smoking on newborn iron stores. Clin Res Trials 2015;1(1):4-7

9 Rehu M, Punnonen K, Ostland V, et al. Maternal serum hepcidin is low at term and independent of cord blood iron status. Eur J Haematol 2010;85(4):345-352

10 Vinter CA, Tanvig MH, Damm P, et al. Obese pregnant women and complications in relation to pregnancy and birth [in Danish]. Ugeskr Laeger 2012;174(16):1079-1082

11 Segovia SA, Vickers MH, Gray C, Reynolds CM. Maternal obesity, inflammation, and developmental programming. Biomed Res Int 2014;2014:418975

12 Galliano D, Bellver J. Female obesity: short- and long-term consequences on the offspring. Gynecol Endocrinol 2013;29(7):626-631

13 Han YS, Ha EH, Park HS, Kim YJ, Lee SS. Relationships between pregnancy outcomes, biochemical markers and pre-pregnancy body mass index. Int J Obes 2011;35(4):570-577

14 Athukorala C, Rumbold AR, Willson KJ, Crowther CA. The risk of adverse pregnancy outcomes in women who are overweight or obese. BMC Pregnancy Childbirth 2010;10:56

15 Garcia-Valdes L, Campoy C, Hayes H, et al. The impact of maternal obesity on iron status, placental transferrin receptor expression and hepcidin expression in human pregnancy. Int J Obes 2015; 39(4):571-578

16 Morton SB, Saraf R, Bandara DK, et al. Maternal and perinatal predictors of newborn iron status. N Z Med J 2014;127(1402): 62-77

17 McLimore HM, Phillips AK, Blohowiak SE, et al. Impact of multiple prenatal risk factors on newborn iron status at delivery. J Pediatr Hematol Oncol 2013;35(6):473-477

18 Shao J, Lou J, Rao R, et al. Maternal serum ferritin concentration is positively associated with newborn iron stores in women with low ferritin status in late pregnancy. J Nutr 2012;142(11):2004-2009

19 Meenakshi SR, Srivastava R, Sharma NR, Kushwaha KP, Aditya V. Obstetric behavior and pregnancy outcome in overweight and obese women: maternal and fetal complications and risks in relation to maternal overweight and obesity. J Obstet Gynaecol India 2012;62(3):276-280 